\title{
Topical medication utilization and health resources consumption in adult patients affected by psoriasis: findings from the analysis of administrative databases of local health units
}

\author{
This article was published in the following Dove Press journal: \\ ClinicoEconomics and Outcomes Research \\ 6 March 2017 \\ Number of times this article has been viewed
}

\section{Valentina Perrone \\ Diego Sangiorgi \\ Stefano Buda \\ Luca Degli Esposti}

Clicon S.r.I. Health, Economics \& Outcomes Research, Ravenna, Italy
Correspondence: Luca Degli Esposti Clicon S.r.l. Health, Economics \& Outcomes Research, Via Salara 36, 48100 Ravenna, Italy

Tel +3954438393

Fax +39544212699

Email luca.degliesposti@clicon.it
Aim: The objectives of this study were to: 1) analyze the drug utilization pattern among adult psoriasis patients who were newly prescribed with topical medication; and 2) assess their adherence to topical therapy and the possibility of switching to other strategies in the treatment process. Methods: An observational retrospective analysis was conducted based on administrative databases of two Italian local health units. All adult subjects who were diagnosed with psoriasis or who were newly prescribed for topical medication with at least one prescription between January 1, 2010, and December 31, 2014, were screened. Only patients who were "non-occasional users of topical drugs" (if they had at least two prescriptions of topical drugs in a time space of 2 years) were considered for the first and second objectives in the analysis. The date of the first prescription of topical agents was identified as the index date (ID), which was then followed for all time available from ID (follow-up period). The adherence to therapy was assessed on the basis of cycles of treatment covered in the 6 months before the end of the follow-up period. The mean health care costs in patients who switched to disease-modifying antirheumatic drugs (DMARDs) or biologics after the ID were evaluated.

Results: A total of 17,860 patients with psoriasis who were newly prescribed for topical medication were identified. A total of 2,477 were identified as "non-occasional users of topical drugs", of whom $70.2 \%$ had a prescription for a topical fixed combination regimen at ID. Around $19 \%$ adhered to their medication, whereas $6 \%$ switched to other options of psoriasis treatment. Multivariable logistic regression model shows that patients on fixed combination treatment were less likely to be non-adherent to treatment and less likely to switch to other treatments. The annual mean pharmaceutical costs were $€ 567.70$ and $€ 10,606.10$ for patients who switched to DMARDs and biologics, respectively.

Conclusion: Our findings show that the use of fixed combination topical treatment can lead to improve the likelihood of patients being adherent to treatment and can decrease the likelihood of switching the treatment to DMARDs or biologics.

Keywords: psoriasis, topical antipsoriatic drugs, real-world data

\section{Introduction}

Psoriasis is a chronic inflammatory skin disorder that impacts negatively on patients' physical and psychological well-being, reduces quality of life, and causes significant economic burden in terms of loss of productivity and increased utilization of health care resources. ${ }^{1}$ Psoriasis is associated with higher risk of developing cardiovascular 
disease, psychiatric/psychologic issues, and psoriatic arthritis. ${ }^{2}$ The accurate etiology of psoriasis is still not completely understood, but a number of possible risk factors are identified such as family history and environmental risk factors. ${ }^{3}$

Psoriasis affects $\sim 2 \%-3 \%$ of the Caucasian population; ${ }^{4,5}$ recent data indicate that the incidence of the disease among the adult population in Italy is $230 / 100,000$ person-years. ${ }^{6}$ In Italy, it has been estimated that about 1.5 million of people are affected by this inflammatory disease. ${ }^{7}$

This chronic disorder has no cure; however, there are many treatment options available whose goal is to reduce disease severity and symptoms. Treatment options include traditional topical therapies such as vitamin D analogs, corticosteroids, dithranol, and tar preparations as first-line therapy. Second-line therapy includes treatment with phototherapy and non-biological systemic agents. Third-line therapy includes systemic biological therapies including treatment with anti-tumor necrosis factor-alpha agents and anti-IL12-23 monoclonal antibody. ${ }^{7-9}$

The choices of treatments depend on many important factors that influence decision making, such as disease severity, location and characteristics of the lesion, and patients' preference. ${ }^{9,10}$ Lack of adherence to topical therapy regimens or incorrect use can cause poor treatment outcomes. ${ }^{11}$ Because the course and symptom of psoriasis vary from person to person, physician must experiment or combine different treatments to ensure that every patient receives best therapy. Recent guidelines have recommended the use of current antipsoriatic therapies in daily practice. ${ }^{8-10,12}$ Topical therapy plays an important role in the treatment of psoriasis and it is considered the most appropriate therapy option for patients with mild-to-moderate disease. ${ }^{10,13}$ However, there is still limited evidence on the management of psoriasis with topical medication in routine clinical practice in Italy.

The objectives of this study were to: 1) analyze the drug utilization pattern among adult psoriasis patients who were newly prescribed with topical medication; and 2) assess their adherence to topical therapy and the possibility of switching to other strategies in the treatment process.

\section{Methods}

\section{Data sources}

The study was based on administrative databases (DBs) of two Italian local health units (LHUs), located in Lombardy and Campania, covering a total population of more than 1.5 million health-assisted individuals. The structure of this database has been described in detail elsewhere. ${ }^{14,15}$
Briefly, the following DBs were used: 1) the healthassisted subjects' DB, which contains patient data such as sex and data of birth; 2) outpatients and inpatients pharmaceutical drugs DB, which contains information regarding prescription records such as the Anatomical-TherapeuticChemical (ATC) code of the drug purchased, the number of packages, the number of units per package, and the dosages; 3) hospital discharge DB, which contains all hospitalization data with discharge diagnosis codes classified according to the International Classification of Diseases, Ninth Revision, Clinical Modification (ICD-9-CM); and 4) finally, the medical exemption register, which contains the records of all disease exemptions, including the exemption code (identifying the disease for which the exemption was granted). The anonymous data file is routinely used by the regional health authorities for epidemiological and administrative purposes. Informed consent is not required for using encrypted retrospective information, according to Italian regulations. As per Italian regulations regarding the conduct of the observational analysis, ${ }^{16}$ this study has been notified to the local Ethics Committee in of the each participating LHU (Pavia, Lombardy; Caserta, Campania) and each LHU Ethics Committee has approved the study.

\section{Study population}

An observational retrospective analysis was conducted. All adult subjects aged $\geq 18$ years with at least one hospitalization with a main or secondary diagnosis of psoriasis (ICD-9-CM code: 696.1) or newly prescribed for topical medications with at least one prescription of topical antipsoriatic drugs (ATC code: D05A) between January 1, 2010, and December 31, 2014, were screened for eligibility. In agreement with recent published evidence, ${ }^{17,18}$ only naïve psoriasis patients who received at least two prescriptions of topical antipsoriatic drugs (ATC code: D05A) in a time space of 2 years were recruited in the analysis. We considered patients who were newly prescribed for topical medications as "occasional users of topical drugs" if they had only one prescription of topical drugs and as "non-occasional users of topical drugs" if they had at least two prescriptions of topical drugs in a time space of 2 years, respectively. Only the cohort of patients who were "non-occasional users of topical drugs" was considered for the first and second objectives in the analysis. Patients were also stratified according to prescription of single component formulations of topical drugs or combined treatment (fixed combination vitamin $\mathrm{D}$ analog [calcipotriol] and corticosteroid [betamethasone dipropionate]). 
The index date (ID) was defined as the data of the first prescription of topical agents in patients with psoriasis in the study period, which represents the enrollment day of each patient, who was then followed for all time available from ID to the last prescription of topical antipsoriatic drugs or to the first switch to other treatment strategies (follow-up period). The number of prescriptions filled for the index drug was recorded. The median length of time that patients continued their index therapy was also evaluated. Patients who were transferred to another LHU and/or patients with concomitant pathologies (rheumatoid arthritis, ankylosing spondylitis, Crohn's disease) were excluded. Additionally, all subjects with unconventional switching between treatment strategies were also excluded (e.g., patients who switched from disease-modifying antirheumatic drugs [DMARDs] to topical agents or from biological drugs to topical agents).

\section{Definitions and study outcomes}

Data on baseline characteristics, including demographics, risk factors, and medical history, were collected. The clinical characteristics of the patients enrolled in this study were also investigated in the 1-year period before the ID. Naïve patients were defined as those who had no prior topical agents prescription filled during the 1 year preceding the enrollment date. Comorbidities were measured using the Charlson comorbidity index. ${ }^{19}$

The adherence to topical therapy was assessed on the basis of cycles of treatment covered during the 6 months before the end of the follow-up period (last topical prescription or switch to DMARDs or biologic therapy). A cycle of treatment with gel formulation and ointment or other formulation was defined as 56 and 28 days, respectively. ${ }^{20}$ Current recommendations on the management of psoriasis 7 suggest that topical agents should be used for almost two treatment cycles before switching to another treatment options such as DMARDs or biological agents. For this reason, we defined that a patient was adherent if there was at least one cycle of treatment in the past 6 months available during the follow-up period.

A switch was defined to occur when a new prescription (say medication B) filled by the patient was for a different product than the previous prescription (say, medication A). The treatment to which the switch occurred could be a systemic or biologic treatment. Switching was evaluated in all the patients included in the study and in a subgroup of patients treated with a fixed combination of calcipotriol and betamethasone dipropionate given as a gel or topical suspension formulation at ID without taking into consideration the last prescription the patient had in the past 6 months. This analysis allowed to evaluate the switch more accurately.

\section{Cost analysis}

The mean health care costs were evaluated in patients with switches to DMARD or biologic agents after the index therapy. Costs are reported in Euros $(€)$. The consumption of health care resources was classified as related or not related to the disease analysis. Drug costs were evaluated using the Italian National Health Service (NHS) purchase price. Hospitalization costs were determined using the diagnosis-related group tariff. The cost of instrumental and laboratory tests was defined according to the tariffs applied by the regions. The cost analysis was conducted from the perspective of the Italian NHS.

\section{Statistical analysis}

We summarized data as mean and standard deviation (median and range as appropriate) for continuous variables and as numbers and percentages for categorical variables. When comparisons were made, groups were assessed and compared using the Students' $t$-test. Qualitative variables were expressed as absolute and relative frequencies.

To identify factors potentially associated with therapeutic switch, a multivariable Cox regression model was used. To assess the proportional hazards assumption, Schoenfeld residuals were analyzed.

Covariates considered in the models were age, sex, adherence to therapy, disease exemption (exemption code: 045.696.1), and/or hospitalization (ICD-9-CM code: 696.1) records, with diagnosis of psoriasis, during the follow-up period. Effect sizes were reported as hazard ratios (HRs) and 95\% confidence intervals (CIs).

Multivariable logistic regression analyses were performed to analyze the effect of various factors on adherence to therapy and to determine the odds ratios (ORs) and 95\% CIs. We used age, sex, and variables that were clinically relevant and significantly associated with adherence in univariate analyses. $p$-values of $\leq 0.05$ were considered to be statistically significant, and all analyses were performed using STATA 12.0 (StataCorp LP, College Station, TX, USA).

\section{Results}

A total of 18,245 study participants were identified in the database with at least one hospitalization with a diagnosis of psoriasis or newly prescribed for topical medications with at least one prescription of topical antipsoriatic drugs between January 1, 2010, and December 31, 2014. All subjects with 
unconventional switching treatment strategies were excluded from analysis $(\mathrm{N}=385)$. Of these, 15,383 patients were identified as patients newly prescribed for topical medications who had only one prescription and were grouped as "occasional users of topical drugs". A total of 2,477 patients were identified as patients newly prescribed for topical medications with at least two prescriptions of topical agents in a time space of 2 years and were grouped as "non-occasional users of topical drugs". Most relevant determinant of exclusion was single prescription of topical antipsoriatic drugs in the 2-year time spaces. Figure 1 shows the details of the inclusion and exclusion criteria of this study.
Table 1 summarizes the baseline characteristics of patients (non-occasional users of topical drugs), stratified according to prescription of topical drugs alone or in fixed combination, adherence to treatment, and switching of therapy. Of the 2,477 patients included in the analysis, the mean (SD) age at the ID was $56.3 \pm 17$ years, of whom 1,359 $(55 \%)$ were males. Of these 2,477 patients, $29.8 \%(n=739)$ had a prescription for monocomponent of topical drugs and $70.2 \%(n=1,738)$ had a prescription for fixed combination therapy at ID (baseline). Among patients who received fixed combination topical treatment, 1,607 had a prescription of a gel formulation and 131 had a prescription of ointment or

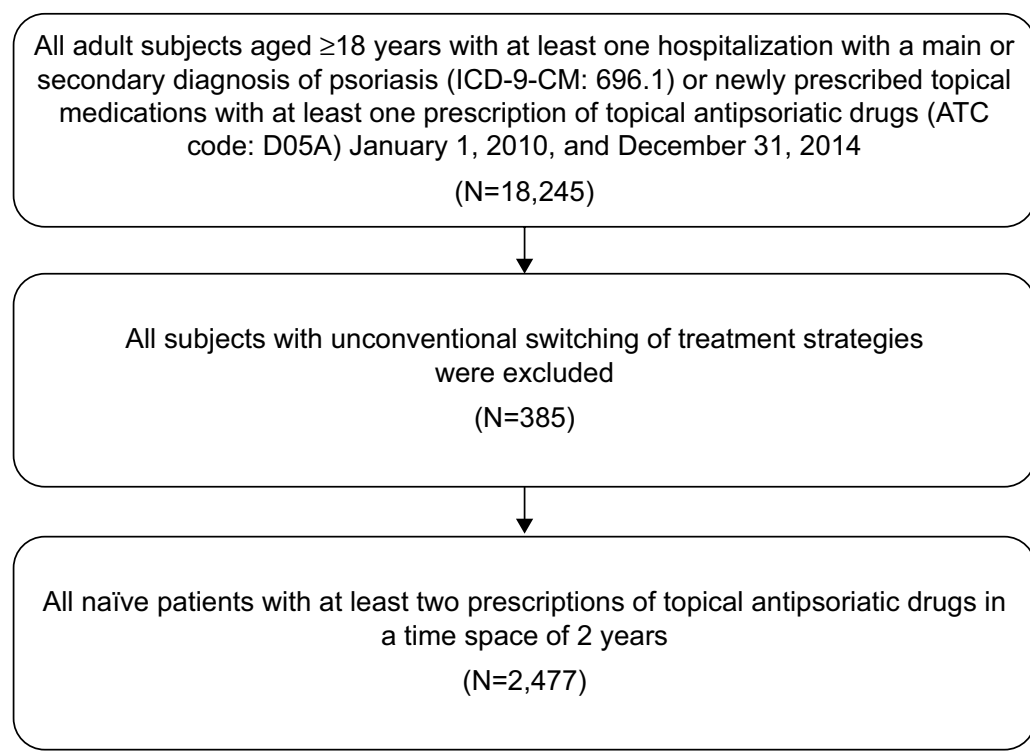

Cohort:

"Non-occasional users of topical drugs"a

Figure I Sequential sample selection of subjects.

Note: alf they had at least two prescriptions of topical drugs in a time space of 2 years.

Abbreviations: ICD-9-CM, International Classification of Diseases, Ninth Revision, Clinical Modification; ATC, anatomical therapeutic chemical.

Table I Baseline of patients, stratified according to topical antipsoriatic drug prescription and level of adherence

\begin{tabular}{|c|c|c|c|c|c|c|c|}
\hline \multirow[t]{2}{*}{ Characteristics } & \multirow{2}{*}{$\begin{array}{l}\text { Total } \\
\text { n (\%) }\end{array}$} & \multicolumn{2}{|l|}{ Topical drugs } & \multicolumn{2}{|l|}{ Adherence } & \multicolumn{2}{|l|}{ Switch } \\
\hline & & $\begin{array}{l}\text { Single-component } \\
\text { formulations }{ }^{\#} \\
\text { n (\%) }\end{array}$ & $\begin{array}{l}\text { Combined } \\
\text { formulations } \\
\text { n (\%) }\end{array}$ & $\begin{array}{l}\text { Yes } \\
\text { n (\%) }\end{array}$ & $\begin{array}{l}\text { No } \\
\text { n (\%) }\end{array}$ & $\begin{array}{l}\text { Yes } \\
\text { n (\%) }\end{array}$ & $\begin{array}{l}\text { No } \\
\text { n (\%) }\end{array}$ \\
\hline $\mathrm{N}$ & $2,477(100)$ & $739(29.8)$ & $\mathrm{I}, 738(70.2)$ & $464(18.7)$ & $2,013(8 \mid .3)$ & $156(6.3)$ & $2,321(93.7)$ \\
\hline Age, years (mean $\pm S D$ ) & $56.3 \pm 17.0$ & $58.2 \pm 16.6$ & $55.5 \pm 17.2$ & $57.4 \pm 17.8$ & $56.1 \pm 16.9$ & $54.0 \pm 15.6$ & $56.5 \pm 17.1$ \\
\hline Male & $\mathrm{I}, 359(55)$ & $391(53)$ & $968(56)$ & $274(59)$ & $\mathrm{I}, 085(54)$ & $82(53)$ & $\mathrm{I}, 277(55)$ \\
\hline $\mathrm{CCl}($ mean $\pm \mathrm{SD})$ & $0.1 \pm 0.4$ & $0.1 \pm 0.5$ & $0.1 \pm 0.4$ & $0.1 \pm 0.5$ & $0.1 \pm 0.4$ & $0.0 \pm 0.2$ & $0.1 \pm 0.4$ \\
\hline $\mathrm{CCl}>0$ & $104(4)$ & $37(5)$ & $67(4)$ & $20(4)$ & $84(4)$ & - & $103(4)$ \\
\hline Disease exemption* and/or & $115(5)$ & $39(5)$ & $76(4)$ & $30(6)$ & $85(4)$ & $32(21)$ & $83(4)$ \\
\hline
\end{tabular}

hospitalization records for

psoriasis**

Notes: *Exemption code: 045.696I; **ICD-9-CM code: 696.I; \#ATC code: D05AX02; \#AATC code: D05AX52.

Abbreviations: SD, standard deviation; CCI, Charlson comorbidity index; ICD-9-CM, International Classification of Diseases, Ninth Revision, Clinical Modification; ATC, anatomical therapeutic chemical. 
topical suspension formulations at baseline. Of the 2,477 patients, the average number of prescriptions filled was 2.6 per year and 2.3 per year for those who received index therapies with a fixed combination and monocomponent, respectively.

The percentage of adherent patients to topical drugs was $18.7 \%(\mathrm{n}=464)$ of a total sample (Table 1$)$; of these patients, $74.6 \%(n=346)$ and $25.4 \%(n=118)$ received index therapies with a fixed combination and monocomponent, respectively. Considering the multivariate predictors of adherence to therapy, a lower $25 \%$ probability of non-adherence was observed among fixed combination therapy users $(\mathrm{OR}=0.755,95 \% \mathrm{CI}$ : 0.599-0.950, $p=0.017$; Table 2).

Among the non-occasional users of topical drugs, approximately $6 \%(n=156)$ of patients switched to other treatment options for psoriasis during the follow-up period (Table 1); of these, $50.6 \%(\mathrm{n}=79)$ patients received fixed combination topical treatment, while $49.4 \%(n=77)$ received monocomponent treatment. With regard to switchers, about $0.5 \%$ of patients switched to a DMARDs and then to a biologic, while $\sim 5 \%$ and $1 \%$ switched to DMARDs and biologics, respectively. The median length of time that switched patients continued their index therapy was 38.2 months.

Among patients treated with fixed combination gel at ID without prescriptions in the past 6 months $(n=695), \sim 10 \%$ $(n=70)$ switched to other treatment options for psoriasis during the follow-up period. About $1 \%$ of this cohort of patients switched to a DMARD and then to a biologic, while $8.2 \%$ and $1 \%$ switched to DMARDs and biologics, respectively. The median length of time that switched patients continued their index therapy was 40.6 months. However, among patients who were treated with ointment or topical suspension formulations of fixed combination at baseline without prescriptions in the past 6 months

Table 2 Predictors of non-adherence: multivariable logistic regression model

\begin{tabular}{lllll}
\hline Predictors & OR & \multicolumn{2}{c}{ 95\% Cl } & P-value \\
\hline Age & 0.994 & 0.988 & 1.000 & 0.070 \\
Male & 0.818 & 0.666 & 1.005 & 0.056 \\
Charlson comorbidity index & 1.056 & 0.829 & 1.346 & 0.658 \\
$\begin{array}{l}\text { Topical drug, fixed combined } \\
\text { formulation\# }\end{array}$ & 0.755 & 0.599 & 0.950 & 0.017 \\
$\begin{array}{l}\text { Disease exemption* and/or } \\
\text { hospitalization records for psoriasis** }\end{array}$ & 0.618 & 0.400 & 0.952 & 0.029 \\
\hline
\end{tabular}

Notes: *Exemption code: 045.696I; **ICD-9-CM code: 696.1; \#ATC code: D05AX02.

Abbreviations: OR, odd ratios; $\mathrm{Cl}$, confidence interval; ICD-9-CM, International Classification of Diseases, Ninth Revision, Clinical Modification; ATC, anatomical therapeutic chemical. $(n=1,782), 5 \%(n=86)$ switched to other treatment options for psoriasis during the follow-up period. Less than $0.5 \%$ of this cohort of patients switched to a DMARD and then to a biologic, while $3.6 \%$ and about $1 \%$ switched to DMARDs and biologics, respectively. The median length of time that switched patients continued their index therapy was 37.5 months.

A multivariable logistic model showed that the use of fixed combination therapy was associated with a lower probability of switching to another treatment $(\mathrm{HR}=0.568$, $p=0.001$ ) (Table 3). Annual health care costs for the management of psoriasis patients based on resource consumption from ID are as follows: $€ 687.6$ for patients who switched to DMARDs, of which about $83 \%$ was spent on drugs (€427.5 specifically related to DMARDs), and $€ 10,776.8$ for patients who switched to biologics, of which about $98 \%$ was spent on drugs (€10,411.7 specifically related to biologics).

\section{Discussion}

This retrospective analysis in an unselected Italian population under clinical practice setting showed that only about $14 \%$ of all patients with psoriasis who were newly prescribed for topical medications had at least two prescriptions of topical agents in a time space of 2 years.

In other words, a significant proportion of psoriasis patients did not receive more than one prescription of topical drugs in the period of analysis. This is consistent with previous findings,${ }^{21}$ and since there was no direct measure of disease severity, the patients on topical treatments may have had limited disease or they may have used topical agents as adjunctive treatment and, therefore, may not have needed continuous treatment. Nevertheless, according to recently published evidence, ${ }^{22,23}$ psoriasis is a chronic disease that requires continuous treatment to achieve optimal control of

Table 3 Predictors of probability of therapy substitution: multivariable proportional hazards Cox regression model

\begin{tabular}{|c|c|c|c|c|}
\hline \multirow{2}{*}{$\begin{array}{l}\text { Predictors } \\
\text { Age }\end{array}$} & \multirow{2}{*}{$\begin{array}{l}\text { HR } \\
0.985\end{array}$} & \multicolumn{2}{|c|}{$95 \% \mathrm{Cl}$} & \multirow{2}{*}{$\begin{array}{l}\text { p-value } \\
0.002\end{array}$} \\
\hline & & 0.975 & 0.994 & \\
\hline Male & 0.996 & 0.724 & 1.370 & 0.979 \\
\hline Charlson comorbidity index & 0.445 & 0.153 & 1.293 & 0.137 \\
\hline Adherence & 0.816 & 0.551 & 1.210 & 0.312 \\
\hline $\begin{array}{l}\text { Topical drug, fixed combined } \\
\text { formulation } \#\end{array}$ & 0.568 & 0.411 & 0.785 & 0.001 \\
\hline $\begin{array}{l}\text { Exemption codes* or hospitalization } \\
\text { for psoriasis** }\end{array}$ & 2.921 & 1.950 & 4.376 & 0.000 \\
\hline
\end{tabular}

Notes: *Exemption code: 045.6961 ; **ICD-9-CM code: 696.1; "ATC code: D05AX02.

Abbreviations: $\mathrm{HR}$, hazard ratios; $\mathrm{Cl}$, confidence interval; ICD-9-CM, International Classification of Diseases, Ninth Revision, Clinical Modification; ATC, anatomical therapeutic chemical. 
inflammatory activity and to minimize skin involvement, despite the fact that disease severity may wax and wane.

Currently, several topical therapies are available and there are both positive and negative aspects to each, but the preferences of patients and clinicians affect the choice of treatment. ${ }^{10}$ The majority of patients enrolled in this study had a prescription for fixed combination vitamin D analog/corticosteroid therapy at ID. In recent years, several studies have reported the efficacy and safety of fixed combination regimens and its advantages compared with individual components. ${ }^{10,24-27}$ Indeed, a recent Cochrane review of this therapy area has shown that use of fixed combination of vitamin $\mathrm{D} /$ corticosteroid could be better compared with individual active components administered alone in patients with mild-moderate psoriasis. ${ }^{13}$ At the same time, real-world evidence suggest that combined treatment with vitamin D analog/corticosteroid therapy is preferred to single components used as monotherapies by most patients with psoriasis. ${ }^{25,28}$

The success of psoriasis treatment depends not only on the efficacy of the medication but also on the patient, for example, patients should follow doctor's advice and the medications prescribed. In patients with psoriasis indicated for antipsoriatic drug treatment, optimal use of psoriasis therapy can limit the physical manifestations of psoriasis and help improve quality of life, but non-adherence is common. ${ }^{29,30}$ Considering that patients with chronic disorders are less likely to be compliant with treatment regimen compared with those with acute conditions; ${ }^{31}$ non-adherence is one of the key factors in the real-life effectiveness of treatments for chronic disorders, such as psoriasis. ${ }^{32}$ Medication non-adherence can have harmful effects on optimal management of psoriasis: non-adherence leads to poor outcomes, more hospitalizations, and significantly higher health care costs. ${ }^{30,33-35}$ Our findings are consistent with previous investigations $^{36,37}$ that demonstrated a suboptimal adherence to topical treatments, likely reflecting the intermittent use of most topical products. For example, in one study, $46 \%$ of patients, who were prescribed topical therapies, reported low levels of adherence and about half of these reported that they use treatment only when they think it is necessary. ${ }^{38}$ Nevertheless, we identified notable variations in the definitions and methodologies of how adherence was measured in previous research, making it difficult to compare the results of the studies assessing this issue.

One of the most relevant aspects of the present study is that the use of combined treatment with vitamin D and corticosteroid for the management of psoriasis could not only reduce the probability of non-adherence to therapy, and our data also showed that use of fixed combination is significantly associated with a lower probability of switching to other antipsoriatic treatments. In accordance with evidence from both randomized controlled trials and real-life data observed in previous analyses, ${ }^{26,28,39,40}$ the complementary mechanisms of action and potentially synergistic effects could lead to an improved tolerability and eventually to a better adherence of the patients. Also, the results of this study are in line with the findings of a published analysis showing that the use of fixed combination topical treatment may offer a good possibility for patients to maintain compliance with their therapy. ${ }^{25,41}$

Psoriasis treatments can be very expensive. ${ }^{11,42-44}$ The costs of antipsoriatic medications vary considerably from relatively cheap topical treatments to highly expensive biological therapies. ${ }^{45}$ Indeed, our study showed that the health care costs in the patients group who switched from topical drugs to DMARDs or biologic agents were considerable. Better treatment strategies could lead to faster clinical improvement and reduction in treatment cost, which would lower the overall expenditure of the health care system and society, allowing increased health investment in other areas.

The findings of this study should be contextualized in light of some limitations. Though the strength of our study is that this approach reflects real-life clinical practice situations, the results must be interpreted in the context of some limitations inherent to any observational study based on administrative DBs. Limitations include 1) lack of important clinical information in the data setting (such as severity of disease and outcome of treatment);2) no lifestyle information was available; 3 ) adherence was estimated using pharmacy data on filled prescriptions, but no data on actual medication consumption were available; 4) the reasons for nonadherence to prescribed treatment among included patients are not retrievable from DBs; and 5) only a relatively limited sample size was analyzed, and the study was performed using the DBs of two LHUs. In addition, as we have focused our analysis on naïve patients who received at least two prescriptions of topical antipsoriatic drugs in a time space of 2 years, classified as "non-occasional users of topical drugs", further studies are necessary to confirm and enhance the generalizability of the findings.

\section{Conclusion}

This retrospective analysis shows that the use of fixed-combination topical treatment can lead to improve the likelihood of patients being adherent to treatment and can decrease the likelihood of switching the treatment to DMARDs or 
biologics. Our findings are potentially helpful in assessing and improving the quality of care for psoriasis patients in clinical practice. Further research using a larger sample of patients are needed to confirm and contextualize our results.

\section{Acknowledgment}

Manuscript development was supported by unconditional funding from LEO Pharma.

\section{Disclosure}

The authors report no conflicts of interest in this work.

\section{References}

1. de Korte J, Sprangers MA, Mombers FM, Bos JD. Quality of life in patients with psoriasis: a systematic literature review. J Investig Dermatol Symp Proc. 2004;9(2):140-147.

2. Griffiths CE, Barker JN. Pathogenesis and clinical features of psoriasis. Lancet. 2007;370(9583):263-271.

3. Huerta C, Rivero E, Rodríguez LA. Incidence and risk factors for psoriasis in the general population. Arch Dermatol. 2007;143(12):1559-1565.

4. Ragnarson Tennvall G, Hjortsberg C, Bjarnason A, et al. Treatment patterns, treatment satisfaction, severity of disease problems, and quality of life in patients with psoriasis in three Nordic countries. Acta Derm Venereol. 2013;93(4):442-445.

5. Nestle FO, Kaplan DH, Barker J. Psoriasis. N Engl J Med. 2009;361(5): 496-509.

6. Parisi R, Symmons DP, Griffiths CEM, Ashcroft DM; Identification and Management of Psoriasis and Associated ComorbidiTy (IMPACT) Project Team. Global epidemiology of psoriasis: a systematic review of incidence and prevalence. J Invest Dermatol. 2013;133(2):377-385.

7. Il trattamento della psoriasi nell'adulto. Linee guida SNLG-SS [The treatment of psoriasis in adults. Guidelines SNLG-SS]. Available from: http://www.snlg-iss.it/cms/files/LG_Psoriasi.pdf. Accessed January 16, 2017.

8. National Clinical Guideline Centre (UK). Psoriasis: Assessment and Management of Psoriasis. London: Royal College of Physicians (UK); 2012 [cited 2015 Aug 24]. (National Institute for Health and Clinical Excellence: Guidance). Available from: http://www.ncbi.nlm.nih.gov/ books/NBK247829/.

9. Menter A, Gottlieb A, Feldman SR, et al. Guidelines of care for the management of psoriasis and psoriatic arthritis: section 1. Overview of psoriasis and guidelines of care for the treatment of psoriasis with biologics. J Am Acad Dermatol. 2008;58(5):826-850.

10. Murphy G, Reich K. In touch with psoriasis: topical treatments and current guidelines. J Eur Acad Dermatol Venereol. 2011;25(Suppl 4):3-8.

11. Colombo GL, Di Matteo S, Bruno G, Girolomoni G, Vena GA. Calcipotriol and betamethasone dipropionate in the treatment of mild-tomoderate psoriasis: a cost-effectiveness analysis of the ointment versus gel formulation. Clinicoecon Outcomes Res. 2012;261-268.

12. Menter A, Korman NJ, Elmets CA, et al; American Academy of Dermatology Work Group. Guidelines of care for the management of psoriasis and psoriatic arthritis: section 6. Guidelines of care for the treatment of psoriasis and psoriatic arthritis: case-based presentations and evidencebased conclusions. J Am Acad Dermatol. 2011;65(1):137-174.

13. Mason AR, Mason J, Cork M, Dooley G, Hancock H. Topical treatments for chronic plaque psoriasis. Cochrane Database Syst Rev. 2013 Mar 28;(3):CD005028.

14. Perrone V, Sangiorgi D, Buda S, Degli Esposti L. Disease progression and health care resource consumption in patients affected by hepatitis C virus in real practice setting. Clinicoecon Outcomes Res. 2016;8:591-597.
15. Degli Esposti L, Sangiorgi D, Buda S, Degli Esposti E, Scaglione F. Therapy discontinuation or substitution in patients with cardiovascular disease, switching among different products of the same off-patent active substance: a 'real-world' retrospective cohort study. BMJ Open. 2016; 6(11):e012003.

16. Agenzia Italiana del Farmaco (AIFA). Guideline for the classification and conduction of the observational studies on medicines. 2010. Available from: https:/www.agenziafarmaco.gov.it/ricclin/sites/default/files/ files_wysiwyg/files/CIRCULARS/Circular\%2031st\%20May\%202010. pdf. Accessed January 16, 2017.

17. Chaptini C, Quinn S, Marshman G. Durable dermatology life quality index improvements in patients on biologics associated with psoriasis areas and severity index: a longitudinal study. Australas J Dermatol. 2016; 57(3): $72-\mathrm{e} 75$.

18. Hernánz JM, Sánchez-Regaña M, Izu R, Mendiola V, García-Calvo C. Clinical and therapeutic evaluation of patients with moderate to severe psoriasis in Spain: the secuence study. Actas Dermosifiliogr. 2012;103(10):897-904.

19. Gonnella JS, Louis DZ, Gozum MV, Callahan CA, Barnes CA. Disease staging clinical and coded criteria. Version 5.26. Ann Arbor, MI: Thomson Medstat; 2010.

20. European Medicine Agency (EMA).Calcipotriol/Betamethasone Summary of Product Characteristics. Available from: http://www. ema.europa.eu/docs/en_GB/document_library/Referrals_document/ Daivobet_30/WC500094997.pdf. Accessed January 16, 2017.

21. Svedbom A, Dalén J, Mamolo C, Cappelleri JC, Petersson IF, Ståhle M. Treatment patterns with topicals, traditional systemics and biologics in psoriasis - a Swedish database analysis. J Eur Acad Dermatol Venereol. 2015;29(2):215-223.

22. Ramirez-Fort MK, Levin AA, Au SC, Gottlieb AB. Continuous versus intermittent therapy for moderate-to-severe psoriasis. Clin Exp Rheumatol. 2013;31(4 Supp1 78):S63-S70.

23. Eissing L, Radtke MA, Zander N, Augustin M. Barriers to guidelinecompliant psoriasis care: analyses and concepts. J Eur Acad Dermatol Venereol. 2016;30(4):569-575.

24. Sticherling M, Eicke C, Anger T. Practicability of combined treatment with calcipotriol/betamethasone gel (Daivobet ${ }^{\circledR} \mathrm{Gel}$ ) and improvement of quality of life in patients with psoriasis. J Dtsch Dermatol Ges. 2013; 11(5):420-427.

25. Hendriks AG, Keijsers RR, de Jong EM, Seyger MM, van de Kerkhof PC. Efficacy and safety of combinations of first-line topical treatments in chronic plaque psoriasis: a systematic literature review. $J$ Eur Acad Dermatol Venereol. 2013;27(8):931-951.

26. Koyama G, Liu J, Scaffidi A, Khazraee M, Epstein B. Novel Approaches to topical psoriasis therapy. Int J Pharm Compd. 2015;19(5):357-365.

27. Rogalski C. Calcipotriol/betamethasone for the treatment of psoriasis: efficacy, safety, and patient acceptability. Psoriasis Targets Ther. 2015; 5:97-107.

28. Neri L, Miracapillo A. Treatment adherence and real-life effectiveness of topical therapy in patients with mild or moderate psoriasis: uptake of scientific evidence in clinical practice and dermatologists' preferences for alternative treatment options. G Ital Dermatol Venereol. 2015;150(1):19-26.

29. Morrill JA, Shrestha M, Grant RW. Barriers to the treatment of hepatitis C. Patient, provider, and system factors. J Gen Intern Med. 2005;20(8): 754-758.

30. Vangeli E, Bakhshi S, Baker A, et al. A systematic review of factors associated with non-adherence to treatment for immune-mediated inflammatory diseases. Adv Ther. 2015;32(11):983-1028.

31. Osterberg L, Blaschke T. Adherence to medication. $N$ Engl J Med. 2005;353(5):487-497.

32. Bewley A, Page B. Maximizing patient adherence for optimal outcomes in psoriasis. J Eur Acad Dermatol Venereol. 2011;25(Suppl 4):9-14.

33. McDonald HP, Garg AX, Haynes RB. Interventions to enhance patient adherence to medication prescriptions: scientific review. JAMA. 2002;288(22):2868-2879. 
34. Devaux S, Castela A, Archier E, et al. Adherence to topical treatment in psoriasis: a systematic literature review. J Eur Acad Dermatol Venereol. 2012;26(Suppl 3):61-67.

35. Feldman SR, Horn EJ, Balkrishnan R, et al; International Psoriasis Council. Psoriasis: improving adherence to topical therapy. J Am Acad Dermatol. 2008;59(6):1009-1016.

36. Nelson PA, Barker Z, Griffiths CE, Cordingley L, Chew-Graham CA; IMPACT Team. 'On the surface': a qualitative study of GPs' and patients' perspectives on psoriasis. BMC Fam Pract. 2013;14:158.

37. Thorneloe RJ, Bundy C, Griffiths CE, Ashcroft DM, Cordingley L. Adherence to medication in patients with psoriasis: a systematic literature review. Br J Dermatol. 2013;168(1):20-31.

38. Bewley A, Burrage DM, Ersser SJ, Hansen M, Ward C. Identifying individual psychosocial and adherence support needs in patients with psoriasis: a multinational two-stage qualitative and quantitative study. J Eur Acad Dermatol Venereol. 2014;28(6):763-770.

39. Daudén E, Bewley A, Lambert J, Girolomoni G, Cambazard F, Reich $\mathrm{K}$. Expert recommendations: the use of the fixed combination calcipotriol and betamethasone dipropionate gel for the topical treatment of psoriasis. J Eur Acad Dermatol Venereol. 2014;28(Suppl 2):22-32.
40. Girolomoni G, Vena GA, Ayala F, et al. Consensus on the use of the fixed combination calcipotriol/betamethasone dipropionate in the treatment of plaque psoriasis. G Ital Dermatol Venereol. 2012;147(6): 609-624.

41. Vakirlis E, Kastanis A, Ioannides D. Calcipotriol/betamethasone dipropionate in the treatment of psoriasis vulgaris. Ther Clin Risk Manag. 2008;4(1):141-148.

42. Feldman SR, Burudpakdee C, Gala S, Nanavaty M, Mallya UG. The economic burden of psoriasis: a systematic literature review. Expert Rev Pharmacoecon Outcomes Res. 2014;14(5):685-705.

43. Svedbom A, Dahlén J, Mamolo C, et al. Economic burden of psoriasis and potential cost offsets with biologic treatment: a Swedish register analysis. Acta Derm Venereol. 2016;96(5):651-657.

44. Burgos-Pol R, Martínez-Sesmero JM, Ventura-Cerdá JM, Elías I, Caloto MT, Casado MÁ. The cost of psoriasis and psoriatic arthritis in 5 European countries: a systematic review. Actas Dermosifiliogr. 2016; 107(7):577-590.

45. Pearce DJ, Thomas CG, Fleischer AB Jr, Feldman SR. The cost of psoriasis therapies: considerations for therapy selection. Dermatol Nurs. 2004;16(5):421-428, 432.
ClinicoEconomics and Outcomes Research

\section{Publish your work in this journal}

ClinicoEconomics and Outcomes Research is an international, peerreviewed open-access journal focusing on health technology assessment, pharmacoeconomics and outcomes research in the areas of diagnosis, medical devices, and clinical, surgical and pharmacological intervention. The economic impact of health policy and health systems
Submit your manuscript here: https://www.dovepress.com/clinicoeconomics-and-outcomes-research-jourat

organization also constitute important areas of coverage. The manuscript management system is completely online and includes a very quick and fair peer-review system, which is all easy to use. Visit http://www.dovepress.com/testimonials.php to read real quotes from published authors. 